\title{
Leishmaniasis revisited: Current aspects on epidemiology, diagnosis and treatment
}

\author{
Sarah P. Georgiadou, Konstantinos P. Makaritsis, George N. Dalekos \\ Department of Medicine and Research Laboratory of Internal Medicine, Medical School, University of Thessaly, \\ Larissa, Greece
}

\section{ABSTRACT}

Leishmaniasis is a vector-borne disease caused by protozoan parasites of the genus Leishmania. It is transmitted by phlebotomine female sand flies of the genera Phlebotomus and Lutzomyia in the old and new world, respectively. More than 20 well-recognized Leishmania species are known to infect humans and cause visceral (VL), cutaneous (CL) and mucocutaneous (ML) forms of the disease. Approximately 350 million people are at risk of contracting the disease and an estimated 1.6 million new cases occur annually. The disease mainly affects poor people in Africa, Asia and Latin America, and is associated with malnutrition, population migration, poor residency conditions, frail immune system and lack of resources. Previously, diagnosis of leishmaniasis relied mainly on invasive techniques of detecting parasites in splenic and bone marrow aspirates. Nevertheless, serological tests using the recombinant kinesin antigen (rK39) and molecular methods (polymerase chain reaction) are considered the best options for diagnosis today, despite problems related to varying sensitivities and specificities and field adaptability. Therapy of leishmaniasis ranges from local treatment of cutaneous lesions to systemic often toxic, therapy for disseminated CL, $M L$ and VL. Agents with efficacy against leishmaniasis include amphotericin B, pentavalent antimonial drugs, paromomycin and miltefosine. No single therapy of VL currently offers satisfactory efficacy along with safety. This article provides a brief and updated systematic review on the epidemiology, diagnosis and treatment of this neglected disease.

Key words: Cutaneous, diagnosis, epidemiology, leishmaniasis, treatment, visceral

\section{INTRODUCTION}

Leishmaniasis is one of the world's most neglected diseases, largely affecting individuals of low socioeconomic level, mainly in developing countries. ${ }^{[1-3]}$ Clinically, the disease is characterized by a diverse spectrum of manifestations that are developed after infection with protozoan parasites of the genus Leishmania. Features of the disease vary widely, but are often divided into three distinct clinical syndromes, namely visceral leishmaniasis (VL) that is potentially a life-threatening condition if untreated, cutaneous leishmaniasis (CL) and mucosal leishmaniasis (ML). ${ }^{[4]}$ A complex interaction between the type of infecting species and the host immune responses seems to be responsible for the development and phenotypic expression of the above-mentioned syndromes in an index patient. In the past 10 years, major scientific breakthroughs have been made in the treatment, diagnosis and prevention of leishmaniasis.

In this brief review, we focus on the current aspects of epidemiology, diagnosis and treatment of this challenging disease.

\section{Epidemiology}

Leishmaniasis is widely distributed across 88 tropical, subtropical and temperate countries, with more than 350 million people at risk. An estimated 12 million patients suffer from leishmaniasis, with 0.2-0.4 million of new VL and 0.7-1.2 million of new CL cases per year worldwide. ${ }^{[1-4]}$ The 
disease mainly affects poor people in Africa, Asia and Latin America, and is associated with malnutrition, population migration, poor residency conditions, frail immune system and lack of resources. ${ }^{[3]}$ Specifically, more than $90 \%$ of VL cases globally occur in six countries: Bangladesh, Brazil, Ethiopia, India, South Sudan and Sudan. ${ }^{[1,4]}$ CL is more widely distributed throughout America, the Mediterranean basin and western Asia. The 10 countries with the highest number of affected cases of CL, which account for $75 \%$ of the global incidence, are Afghanistan, Algeria, Brazil, Colombia, Costa Rica, Ethiopia, Iran, Peru, North Sudan and Syria. ${ }^{[1,4,5]}$

Overall, infection is caused by more than 20 species of Leishmania parasites, which are spread by approximately 30 species of phlebotomine sand flies. Female sand flies of the genus Lutzomyia in America (new world) and Phlebotomus in the rest of the world (old world) transmit Leishmania spp. The sand fly vectors generally are most active after evening, in the night-time hours ("from dusk to dawn"). ${ }^{[4]}$ Climate and other environmental changes have the potential to expand the geographic range of the sand fly vectors and the areas in the world where leishmaniasis is found. ${ }^{[6]}$ Typically, leishmaniasis is transmitted by the bite of an infected female sand fly to mammalian reservoirs, such as rodents, marsupials, edentates, monkeys and wild or domestic canines. Humans are infected incidentally in endemic areas. ${ }^{[7]} \mathrm{VL}$ can also be transmitted via intravenous drug use, blood transfusion, organ transplantation, congenital infection and laboratory accidents, although these modes of transmission are relatively rare. ${ }^{[8-10]}$

Anthroponotic transmission is characteristic of the L. tropica complex (old world) and $L$. donovani complex (especially in the Indian subcontinent). ${ }^{[1]} \mathrm{L}$. donovani occurs in South Asia (India, Bangladesh and Nepal) and East Africa (Sudan, Ethiopia, Kenya, Somalia). In areas with anthroponotic transmission, effective treatment of patients can help control the spread of the parasite. Clinical disease due to $L$. donovani can affect people of all ages, although in regions with constant endemic transmission the incidence may fall with increasing age because of a high rate of acquired immunity in older adults. ${ }^{[12]}$ In East Africa, $L$. donovani is the cause of both anthroponotic and zoonotic disease. ${ }^{[13-18]}$

On the contrary, L. infantum-VL (synonym to L. chagasi) occurs in the Mediterranean, the Middle East, Afghanistan, Iran, Pakistan and Brazil, although sporadic cases have been reported in Central Asia, China, Mexico and Central and Latin America. ${ }^{[11,19]}$ Notably, children and immunosuppressed adults are at higher risk of clinical disease due to $L$. infantum than immunocompetent adults. ${ }^{[20,21]}$ Transmission of $L$. infantum infection is considered predominantly zoonotic, with domestic dog being the major reservoir. ${ }^{[19,22]}$

The high prevalence of asymptomatic human carriers of $L$. infantum in southern Europe suggests that this parasite is a latent public health menace. ${ }^{[23]}$ Whereas most immunocompetent individuals will not develop clinical disease after this parasitic infection, potential administration or acquired development of immunosuppression would result in the emergence of clinically severe disease. ${ }^{[21,23,24]}$ In this context, an increase of co-infections with human immunodeficiency virus (HIV) and Leishmania has been observed during the last 30 years. ${ }^{[25]}$ Cases of co-infection have been reported in the Mediterranean region, mainly in France, Italy, Portugal and Spain. Moreover, VL is an emerging condition affecting HIV-infected patients living in many Asian (especially India) and African countries as well as in Latin America, particularly in Brazil. ${ }^{[26]}$ The majority of non-HIV-related immunosuppressive conditions that are associated with VL emergence have been reported in the field of transplantation medicine, rheumatology, oncology and hematology. ${ }^{[21]}$ In the last 20 years, the increasing frequency of organ transplantations and the improvement on immunosuppressive treatments have led to the recognition of several cases of VL after organ transplantation. ${ }^{[27,28]}$ In addition, introduction of tumor necrosis factor-alfa (TNF-alfa) blockade into the clinical practice has been associated with increasing reports of leishmaniasis in patients with autoimmune rheumatic diseases who live in endemic areas. ${ }^{[2,30]}$ Moreover, several cases have been reported in patients under treatment with various immunomodulatory drugs, like azathioprine, methotrexate, steroids and cyclosporine. ${ }^{[31,32]}$ Thus, it is recommended that patients living in or returning from areas endemic for leishmaniasis should undergo serological screening before immunosuppressive treatment.

\section{Diagnosis}

The diagnosis of all suspected Leishmania infections can be approached by three ways: clinical, parasitological and immunologic. A clinical diagnosis can have a very high pretest probability in some settings. For example, the presence of high-grade fever in association with cytopenias, remarkable splenomegaly and significant polyclonal increase of $\gamma$-globulins (especially of $\mathrm{IgG}$ class) in the appropriate epidemiological setting make the diagnosis of VL easy. ${ }^{[33]}$ However, specific laboratory testing is needed to establish the diagnosis of VL. Definitive diagnosis requires the demonstration of parasite by smear or culture in affected organs tissues. ${ }^{[34]}$ Usually, bone marrow or spleen aspirations are performed (sensitivity $70 \%$ and $96 \%$ in one comparative analysis of parasitological methods). ${ }^{[3]}$ Nevertheless, splenic aspiration is associated with increased risk of substantial hemorrhage or bowel perforation. 
These risks are reported low in experienced medical centers, but complications can be fatal. ${ }^{[36,37]}$ Therefore, splenic puncture has been restricted only in patients with a skewed diagnosis and no laboratory evidence of coagulopathy, whereas the procedure should be performed only by an experienced operator. Bone marrow aspirates are definitely safer than splenic aspirates and preferred in the every-day clinical practice in the nonendemic settings, although they are less sensitive (40-70\%). ${ }^{[37-39]}$ The wide range of detection on bone marrow specimens reflects the stage of the disease and also the rigor of the microscopic review as in a previous study the sensitivity of bone marrow examination was associated with the duration of microscopic investigation $(66 \%$ and $92 \%$ at 5 min and 1 $\mathrm{h}$, respectively). $\cdot{ }^{[40]}$ Liver biopsy is less likely to yield the diagnosis, but occasionally may contribute, particularly when in the appropriate clinical and epidemiological setting, serology and bone marrow investigations are unrevealing. ${ }^{[41]}$ Lymph node aspiration or biopsy may be diagnostic when enlarged nodes are present. ${ }^{[42]}$ Definite diagnosis requires visualization of amastigotes, which are spherical or ovoid bodies that measure 1-5 microns long by 1-2 microns wide. Amastigotes are usually found within macrophages and are characterized by a large nucleus and a rod-like organelle called the kinetoplast, made up of tightly concatenated extranuclear DNA.

Whenever feasible, samples from the spleen, bone marrow, liver, cutaneous lesions or lymph nodes should be cultured. Culture can be performed in Novy-McNeal-Nicolle (NNN) or several other growth media. ${ }^{[36]}$ In appropriate culture media, tissue amastigotes are converted to motile promastigotes and then multiply in vitro. The culture is checked weekly for up to 4 weeks after inoculation. Growth usually occurs within 2 weeks, but may take longer using material with low parasite inoculum. The sensitivity of cultures depends on the parasite load, but is estimated to be between $60 \%$ and $85 \% \cdot{ }^{[43,44]}$

VL infection induces intense activation of innate immunity pathways along with polyclonal B cell stimulation, leading sometimes to the development of hemophagocytic syndrome and production of a broad range of autoantibodies, which in turn can result in misdiagnosis (like autoimmune hepatitis or systemic lupus erythematosus) or underdiagnosis of the disease, especially in areas of low to moderate endemicity. ${ }^{[45-48]}$ However, a number of serologic tests using specific different antigens of the parasite are available in an attempt to speed up a timely and correct diagnosis. ${ }^{[49]}$ The adoption of various serologic assays may vary by geographic region and by host factors. For instance, the sensitivity of serologic testing is generally lower in HIV-co-infected patients, particularly if HIV infection preceded the Leishmania infection. ${ }^{[50]}$
In addition, the assays that use whole parasite antigens have a higher sensitivity but relatively lower specificity because of cross-reactivity with antigens of Chagas disease, malaria and other infections, as well as nonspecific cross-reactivity. ${ }^{[51]}$ Nonetheless, indirect fluorescent antibody tests (IFA) and enzyme-linked immunosorbent assays (ELISAs) are useful diagnostic tools. ${ }^{[34]}$ The direct agglutination test (DAT) is another diagnostic tool, easily read by direct vision, which requires less equipment than ELISA and, therefore, it can be applied in low-resources settings. ${ }^{[2,53]}$ It should be noted that patients with clinical recovery after successful treatment of VL continue to have positive serum antibodies against Leishmania spp. for months to years; therefore, these assays cannot be used reliably as tests of treatment response and cure of the disease. Similarly, a positive serological test is not by definition a proof of evidence of active VL; for this reason, such results must be interpreted with caution taking into account both clinical and epidemiological information. ${ }^{[54]}$ In addition, the diagnostic role of serology in the diagnosis of CL is limited; the sensitivity and specificity are variable and antibody levels are generally low.

Most promising results are shown by recombinant kinesin antigen (rk39) with sensitivity and specificity of $100 \%$ and $96 \%$, respectively. ${ }^{[5]}$ Moreover, the antibody titers to this antigen are directly associated with active disease and have the advantage of monitoring after anti-parasitic treatment and in predicting the clinical relapse. ${ }^{[5,57]}$ This antigen has also been used in immunochromatographic strips as a rapid test that requires minimal equipment and is easy to use in developing settings. ${ }^{[58]}$

Urine leishmanial antigen assay or kala-azar latex agglutination test (KAtex) is also a useful diagnostic test, especially in difficult field conditions, as it is simple, easy to perform, does not require any equipment and is read visually. KAtex has high specificity but its sensitivity is $<70 \%$, limiting its diagnostic utility. In addition, this assay becomes negative rapidly after successful treatment. ${ }^{[59-61]}$

Molecular-based diagnostic methods [polymerase chain reaction (PCR)] are highly sensitive and specific assays for the detection of Leishmania DNA and the differentiation of species particularly when whole blood or bone marrow specimens are being tested and, therefore, are considered the cornerstone in the clinical algorithm of primary diagnosis of VL, especially in cases of HIV co-infection. ${ }^{[2,63]}$ PCR sensitivity is higher than that of smear or culture, but is variable depending on the tissue used. Indeed, in our hands, a retrospective analysis of 67 patients with well-established VL, showed a sensitivity of PCR in peripheral blood, bone marrow or both specimens in $91 \%, 72 \%$ and $100 \%$ of patients, respectively, whereas the corresponding data 
on direct bone marrow microscopy and positive serology were found in $54 \%$ and $41 \%$, respectively (Georgiadou and Dalekos personal unpublished data, 2014). A few studies have also demonstrated that PCR assays can be used as tests of cure, being the most useful techniques for monitoring the long-term drug efficacy and for identifying relapses. ${ }^{[21,63-66]}$ However, lack of detailed standardization and global homogenization and validation together with the reduction of specificity in endemic areas are the main disadvantages of these useful diagnostic tools, ${ }^{[6]}$ whereas PCR positivity does not distinguish asymptomatic infection from true active disease. Moreover, they are cumbersome to perform and have a relatively high cost. A proposed algorithm for $\mathrm{VL}$ diagnosis is shown in Figure 1.

\section{Treatment}

Without anti-parasitic treatment, the case fatality rate of clinical VL (kala-azar) is estimated to be more than $90 \%$. Mortality is often due to hemorrhagic or infectious complications. ${ }^{[4]}$ Agents with efficacy against leishmaniasis

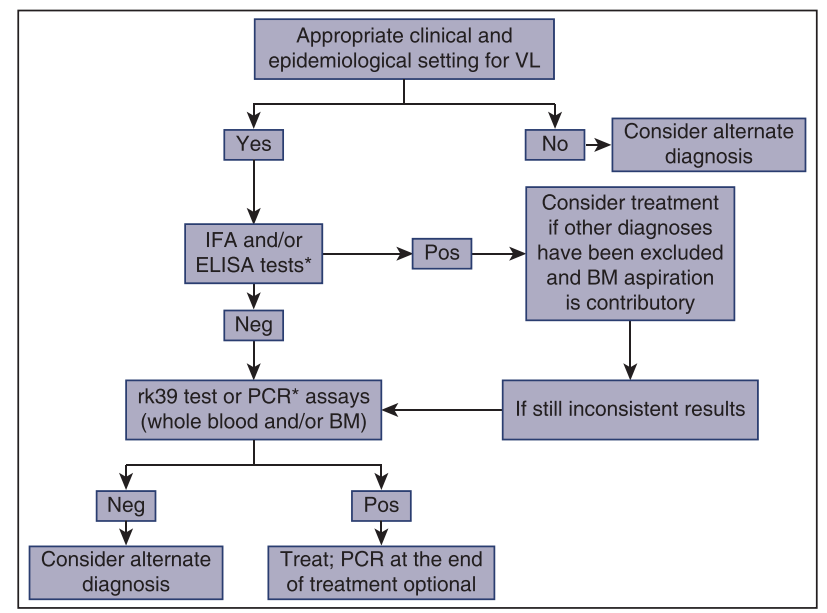

Figure 1: A proposed diagnostic algorithm for visceral leishmaniasis (VL). IFA, indirect fluorescent antibody test; ELISA, enzyme-linked immunosorbent assay; Pos, positive; Neg, negative; PCR, polymerase chain reaction; BM, bone marrow; *PCR should be preferred as the initial screening test in immunocompromised hosts. include amphotericin B, pentavalent antimonial drugs, paromomycin and miltefosine [Table 1]. ${ }^{[4]}$ Undoubtedly, liposomal amphotericin B (L-AMB) is the drug of choice for the treatment of VL in any setting where it can be safely administered and cost is not limiting as it has the highest therapeutic efficacy and the most favorable safety profile. ${ }^{[68,69]}$ L-AMB is the only drug with US Food and Drug Administration (FDA) approval for VL treatment in the United States and, according to the World Health Organization (WHO), a total cumulative dose of $20 \mathrm{mg} / \mathrm{kg}$ is adequate to achieve high cure rates in immunocompetent patients with VL worldwide, regardless of the specific dosing schedule. ${ }^{[68]}$ However, the FDA-approved regimen for immunocompetent patients is $3.0 \mathrm{mg} / \mathrm{kg}$ of body weight per day on Days 1-5, 14 and 21 [Table 1]. ${ }^{[70]}$ In addition, as immunosuppressed patients have higher disseminated parasite loads, lipid formulations infused at a dose of $3-5 \mathrm{mg} / \mathrm{kg}$ daily or intermittently for 10 doses (days $1-5$, $10,17,24,31$ and 38) up to a total dose of $40-60 \mathrm{mg} / \mathrm{kg}$ are recommended. ${ }^{[21]}$ Nevertheless, treatment failure and relapse rates are particularly high in cases of impaired cellular immunity, especially in HIV co-infections. ${ }^{[21]}$ The usual strategy in these cases is to re-treat with L-AMB as the parasite does not necessarily develop resistance to this drug even after repetitive courses or prophylactic use. ${ }^{[71]}$ Secondary prophylaxis reduces the rate of recurrences, although optimal regimens or duration of prophylaxis have not been defined yet. ${ }^{[2,73]}$ It should be noted that several other formulations like amphotericin B lipid complex and amphotericin B colloidal dispersion have also been used. All of them are similar to amphotericin B deoxycholate concerning their efficacy but are significantly less toxic. ${ }^{[74]}$ Mild infusion reactions (fever, chills and rigor) and back pain occur in some cases. Transient nephrotoxicity is also occasionally seen..$^{[75]}$ Rarely, reversible drug-related myocarditis and subclinical tumor-lysis like syndrome have also been reported. ${ }^{[7,77]}$

The pentavalent antimonial drugs, sodium stibogluconate and meglumine antimoniate, have been the standard

\begin{tabular}{|c|c|c|c|c|}
\hline Agent & Dose & Response rates & Side-effects & Other comments \\
\hline L-AMB & $\begin{array}{l}3 \mathrm{mg} / \mathrm{kg} / \mathrm{d} \text { on Days } 1-5,14 \\
\text { and } 21 \text { (IV) }\end{array}$ & $\begin{array}{l}>90 \% \text { in } 1 \text { cycle; } \\
95-97 \% \text { after } \\
2 \text { cycles }\end{array}$ & $\begin{array}{l}10-20 \% \text { (mild infusion } \\
\text { reactions, back pain, } \\
\text { transient nephrotoxicity) }\end{array}$ & $\begin{array}{l}\text { Immunosuppressed patients: } \\
3-5 \mathrm{mg} / \mathrm{kg} / \mathrm{d} \text { on Days } 1-5 \text {, } \\
10,17,24,31 \text { and } 38 \text { (total } \\
\text { dose: } 40-60 \mathrm{mg} / \mathrm{kg} \text { ) }\end{array}$ \\
\hline $\begin{array}{l}\text { Pentavalent } \\
\text { antimonial } \\
\text { drugs }\end{array}$ & $\begin{array}{l}20 \mathrm{mg} / \mathrm{kg} / \mathrm{d} \text { for } 28-30 \text { days } \\
\text { (IV or IM) }\end{array}$ & $>90 \%$ & $\begin{array}{l}\text { Usually elevation of LFTs } \\
\text { and cytopenias; serious: } \\
\text { Cardiotoxicity, pancreatitis }\end{array}$ & $\begin{array}{l}\text { High resistance in some areas } \\
(60 \%)\end{array}$ \\
\hline Miltefosine & $\begin{array}{l}2.5 \mathrm{mg} / \mathrm{kg} / \mathrm{d}(2-11 \text { years }) \\
50 \mathrm{mg} / \mathrm{d}(<25 \mathrm{~kg}) ; 100 \\
\mathrm{mg} / \mathrm{d}(25-50 \mathrm{~kg}) ; 150 \mathrm{mg} / \mathrm{d} \\
(>50 \mathrm{~kg}) . \text { Orally } 28 \text { days }\end{array}$ & $80-90 \%$ & $\begin{array}{l}\text { Gastrointestinal, LFTs } \\
\text { elevation, potentially } \\
\text { teratogenic }\end{array}$ & $\begin{array}{l}\text { Concerns for high failure } \\
\text { rates }(10-20 \%) \text {; adherence } \\
\text { questionable }\end{array}$ \\
\hline Paromomycin & $15 \mathrm{mg} / \mathrm{kg} / \mathrm{d}$ for 21 days (IM) & $80-95 \% *$ & $\begin{array}{l}\text { Uncommon (ototoxicity, } \\
\text { LFTs increase, renal injury) }\end{array}$ & No experience for $L$. infantum \\
\hline
\end{tabular}

*Referring to India and East Africa; L-AMB, liposomal amphotericin; IV, intravenously; IM, intramuscularly; LFTs, liver function tests 
first-line treatment in most parts of the world $(>90 \%$ overall cure rate), ${ }^{[78]}$ but drug resistance is a major problem in the Bihar focus, India and in Nepal, where unresponsiveness is as high as $60 \%$, although this does not necessarily represent parasite resistance [Table 1]. ${ }^{[79-81]}$ Initial treatment should be based on a daily injection of $20 \mathrm{mg} / \mathrm{kg}$ body weight (intravenous or intramuscular) for $28-30$ days. ${ }^{[82]}$ Toxicity is usually related to the cumulative dose. The most serious adverse effects are cardiotoxicity and clinical pancreatitis, either of which can lead to death. Furthermore, elevation of liver enzymes, leukopenia, anemia and thrombocytopenia are not uncommon. ${ }^{[82]}$

An important new drug for the treatment of VL is miltefosine, an orally administered phosphocholine analogue that was initially developed as an antineoplastic agent [Table 1]. Nevertheless, in 2002, it was registered in India for the treatment of VL. ${ }^{[83]}$ Miltefosine commonly induces gastrointestinal side-effects such as anorexia, nausea, vomiting (38\%) and diarrhea (20\%) and elevated liver enzymes. Moreover, it is potentially teratogenic and should not be used in pregnancy or in women with child-bearing potential. ${ }^{[83]}$ Miltefosine is given at a dose of $2.5 \mathrm{mg} / \mathrm{kg}$ per day for 28 days to children aged 2-11 years and for subjects aged 12 years and above at a dose of $50 \mathrm{mg} /$ day for those weighing $<25 \mathrm{~kg}$, $100 \mathrm{mg} /$ day for $25-50 \mathrm{~kg}$ body weight and $150 \mathrm{mg} /$ day for $>50 \mathrm{~kg}$ body weight for 28 days [Table 1]. Adherence to a 28 -day oral regimen with a drug that may cause gastrointestinal side-effects is questionable. ${ }^{[84]}$ There is a real concern that sub-therapeutic dosing of a single drug with a long half-life could lead to the development of resistance. ${ }^{[85,86]}$ Of note, data from long-term follow-up studies have suggested that failure rates may reach $10 \%$ at 6 months and $20 \%$ at 12 months, which is considered to be an alarming signal for the VL elimination campaign. ${ }^{[87-89]}$

Paromomycin, an injectable aminoglycoside, has also been shown to be effective in Indian VL and was licensed in India in 2006 as a dose of $15 \mathrm{mg} / \mathrm{kg}$ paromomycin sulfate for 21 days led to a cure rate of $93-95 \% \cdot{ }^{[90]}$ However, the efficacy was lower (80-85\%) in East Africa, although an increased dose of $20 \mathrm{mg} / \mathrm{kg}$ per day for 21 days was used. ${ }^{[1]}$ There is no experience with this drug in $L$. infantum foci (Mediterranean, South America). Adverse events are uncommon and include transient elevation of liver enzymes, reversible ototoxicity and renal insufficiency. ${ }^{[0]}$ Topical and oral forms of paromomycin have been used for the treatment of CL. ${ }^{[92]}$

Many investigators worldwide suggest combination chemotherapy regimens for VL in endemic areas. Combination therapies have the potential advantages of shortening the duration of treatment and reducing the overall dose of medicines thus decreasing both toxicity and cost while preventing the emergence of resistance. Single-dose L-AMB plus a short course with miltefosine is particularly attractive in India, and a combination of sodium stibogluconate and paromomycin has been used in Sudan. ${ }^{[93,94]}$ Another clinical trial has compared L-AMB with miltefosine, L-AMB and paromomycin and miltefosine plus paromomycin sulfate; all combinations were noninferior to the standard treatment with amphotericin B. ${ }^{[95]}$

Finally, it should be noted that supportive treatment is also important; patients should receive proper hydration and nutritional supplementation. Severe anemia should be corrected with blood transfusions and concomitant infections should be treated with appropriate antibiotics. Successful therapy improves the general condition, resolves fever and causes regression of splenomegaly and recovery of blood counts toward normal. ${ }^{[4]}$

\section{CONCLUSIONS}

Leishmaniasis consists of a complex of vector-borne diseases caused by a heterogeneous group of protozoa belonging to the genus Leishmania. Clinical manifestations range from cutaneous ulcers to systemic multiorgan disease. Molecular methods contribute significantly to a prompt and timely diagnosis of leishmaniasis in an attempt to decrease the remarkable morbidity and mortality that still carries the disease. Although there are several anti-parasitic agents, L-AMB, wherever available, has the highest therapeutic efficacy and the most favorable safety profile. Immunosuppressed patients may have severe and/or atypical clinical presentations and may respond poorly to treatment. Taking into consideration the lack of a commercially available vaccine, the growing number of immunosuppressed patients, the lack of access to therapy in the developing countries and the limited local resources of the affected countries, it is concluded that elimination of the disease is still a challenge for the international health community.

\section{REFERENCES}

1. Alvar J, Vélez ID, Bern C, Herrero M, Desjeux P, Cano J, et al. Leishmaniasis worldwide and global estimates of its incidence. PLoS One 2012;7:e35671.

2. Mathers CD, Ezzati M, Lopez AD. Measuring the burden of neglected tropical diseases: The global burden of disease framework. PLoS Negl Trop Dis 2007;1:e114.

3. Alvar J, Yactayo S, Bern C. Leishmaniasis and poverty. Trends Parasitol 2006;22:552-7.

4. Murray HW, Berman JD, Davies CR, Saravia NG. Advances in leishmaniasis. Lancet 2005;366:1561-77.

5. Nateghi Rostami M, Saghafipour A, Vesali E. A newly emerged cutaneous leishmaniasis focus in central Iran. Int J Infect Dis. 2013;17:e1198-206.

6. Sutherst RW. Global change and human vulnerability to vector-borne diseases. Clin Microbiol Rev 2004;17:136-73. 
7. Quinnell RJ, Courtenay O. Transmission, reservoir hosts and control of zoonotic visceral leishmaniasis. Parasitology 2009;136:1915-34.

8. Dey A, Singh S. Transfusion transmitted leishmaniasis: A case report and review of literature. Indian J Med Microbiol 2006;24:165-70.

9. Antinori S, Cascio A, Parravicini C, Bianchi R, Corbellino M. Leishmaniasis among organ transplant recipients. Lancet Infect Dis 2008;8:191-9.

10. Meinecke CK, Schottelius J, Oskam L, Fleischer B. Congenital transmission of visceral leishmaniasis (Kala Azar) from an asymptomatic mother to her child. Pediatrics 1999;104:e65.

11. Bern C, Maguire JH, Alvar J. Complexities of assessing the disease burden attributable to leishmaniasis. PLoS Negl Trop Dis 2008;2:e313.

12. Bern C, Amann J, Haque R, Chowdhury R, Ali M, Kurkjian KM, et al. Loss of leishmanin skin test antigen sensitivity and potency in a longitudinal study of visceral leishmaniasis in Bangladesh. Am J Trop Med Hyg 2006;75:744-8.

13. Elnaiem DA, Hassan HK, Ward RD. Phlebotomine sandflies in a focus of visceral leishmaniasis in a border area of eastern Sudan. Ann Trop Med Parasitol 1997;91:307-18.

14. Bucheton B, Kheir MM, El-Safi SH, Hammad A, Mergani A, Mary C, et al. The interplay between environmental and host factors during an outbreak of visceral leishmaniasis in eastern Sudan. Microbes Infect 2002;4:1449-57.

15. Alvar J, Bashaye S, Argaw D, Cruz I, Aparicio P, Kassa A, et al. Kala-azar outbreak in Libo Kemkem, Ethiopia: Epidemiologic and parasitologic assessment. Am J Trop Med Hyg 2007;77:275-82.

16. Seaman J, Mercer AJ, Sondorp E. The epidemic of visceral leishmaniasis in western Upper Nile, southern Sudan: Course and impact from 1984 to 1994. Int J Epidemiol 1996;25:862-71.

17. Elnaiem DA, Hassan MM, Maingon R, Nureldin GH, Mekawi AM, Miles M, et al. The Egyptian mongoose, Herpestes ichneumon, is a possible reservoir host of visceral leishmaniasis in eastern Sudan. Parasitology 2001;122:531-6.

18. Dereure J, El-Safi SH, Bucheton B, Boni M, Kheir MM, Davoust B, et al. Visceral leishmaniasis in eastern Sudan: Parasite identification in humans and dogs; host-parasite relationships. Microbes Infect 2003;5:1103-8.

19. Ready PD. Leishmaniasis emergence in Europe. Euro Surveill 2010;15:19505.

20. Kafetzis DA, Maltezou HC. Visceral leishmaniasis in paediatrics. Curr Opin Infect Dis 2002;15:289-94.

21. van Griensven J, Carrillo E, López-Vélez R, Lynen L, Moreno J. Leishmaniasis in immunosuppressed individuals. Clin Microbiol Infect 2014;20:286-99.

22. Chitimia L, Muñoz-García CI, Sánchez-Velasco D, Lizana V, Del Río L, Murcia L, et al. Cryptic Leishmaniosis by Leishmania infantum, a feature of canines only? A study of natural infection in wild rabbits, humans and dogs in southeastern Spain. Vet Parasitol 2011;181:12-6.

23. Michel G, Pomares C, Ferrua B, Marty P. Importance of worldwide asymptomatic carriers of Leishmania infantum (L. chagasi) in human. Acta Trop 2011;119:69-75.

24. Singh OP, Hasker E, Sacks D, Boelaert M, Sundar S. Asymptomatic Leishmania infection: A new challenge for Leishmania control. Clin Infect Dis 2014;58:1424-9.

25. Jarvis JN, Lockwood DN. Clinical aspects of visceral leishmaniasis in HIV infection. Curr Opin Infect Dis 2013;26:1-9.

26. Alvar J, Aparicio P, Aseffa A, Den Boer M, Cañavate C, Dedet JP, et al. The relationship between leishmaniasis and AIDS: The second 10 years. Clin Microbiol Rev 2008;21:334-59.

27. Clemente WT, Faria LC, Romanelli RM, Lima SS, Cortes JR, Oliveira AP, et al. Visceral leishmaniasis in liver transplant recipients from an endemic area. Transplantation 2011;91:806-8.

28. Bouchekoua M, Trabelsi S, Ben Abdallah T, Khaled S. Visceral leishmaniasis after kidney transplantation: Report of a new case and a review of the literature. Transplant Rev (Orlando) 2014;28:32-5.

29. Xynos ID, Tektonidou MG, Pikazis D, Sipsas NV. Leishmaniasis, autoimmune rheumatic disease, and anti-tumor necrosis factor therapy, Europe. Emerg Infect Dis 2009;15:956-9.

30. Guedes-Barbosa LS, Pereira da Costa I, Fernandes V, Henrique da Mota LM, de Menezes I, Aaron Scheinberg M. Leishmaniasis during anti-tumor necrosis factor therapy: Report of 4 cases and review of the literature (additional 28 cases). Semin Arthritis Rheum 2013;43:152-7.
31. Erre GL, Mesina P, Tonelli N, Passiu G. Visceral Leishmaniasis among immunosuppressed patients with rheumatic diseases. Clin Exp Rheumatol 2010;28:590-1.

32. Bogdan C. Leishmaniasis in rheumatology, haematology and oncology: Epidemiological, immunological and clinical aspects and caveats. Ann Rheum Dis 2012;71 Suppl 2:i60-6.

33. Singh SP, Picado A, Boelaert M, Gidwani K, Andersen EW, Ostyn B, et al. The epidemiology of Leishmania donovani infection in high transmission foci in India. Trop Med Int Health 2010;15:12-20.

34. Srivastava P, Dayama A, Mehrotra S, Sundar S. Diagnosis of visceral leishmaniasis. Trans R Soc Trop Med Hyg 2011;105:1-6.

35. Zijlstra EE, Ali MS, el-Hassan AM, el-Toum IA, Satti M, Ghalib HW, et al. Kala-azar: A comparative study of parasitological methods and the direct agglutination test in diagnosis. Trans R Soc Trop Med Hyg 1992;86:505-7.

36. Sundar S, Rai M. Laboratory diagnosis of visceral leishmaniasis. Clin Diagn Lab Immunol 2002;9:951-8.

37. Thakur CP. A comparison of intercostal and abdominal routes of splenic aspiration and bone marrow aspiration in the diagnosis of visceral leishmaniasis. Trans R Soc Trop Med Hyg 1997;91:668-70.

38. Sarker CB, Alam KS, Jamal MF, Rahman S, Huq MH, Musa AK, et al. Sensitivity of splenic and bone marrow aspirate study for diagnosis of kala-azar. Mymensingh Med J 2004;13:130-3.

39. Siddig M, Ghalib H, Shillington DC, Petersen EA. Visceral leishmaniasis in the Sudan: Comparative parasitological methods of diagnosis. Trans R Soc Trop Med Hyg 1988;82:66-8.

40. Lightner LK, Chulay JD, Bryceson AD. Comparison of microscopy and culture in the detection of Leishmania donovani from splenic aspirates. Am J Trop Med Hyg 1983;32:296-9.

41. Artan R, Yilmaz A, Akçam M, Aksoy NH. Liver biopsy in the diagnosis of visceral leishmaniasis. J Gastroenterol Hepatol 2006;21:299-302.

42. Babiker ZO, Davidson R, Mazinda C, Kipngetich S, Ritmeijer K. Utility of lymph node aspiration in the diagnosis of visceral leishmaniasis in Sudan. Am J Trop Med Hyg 2007;76:689-93.

43. Gatti S, Gramegna M, Klersy C, Madama S, Bruno A, Maserati R, et al. Diagnosis of visceral leishmaniasis: The sensitivities and specificities of traditional methods and a nested PCR assay. Ann Trop Med Parasitol 2004;98:667-76.

44. Brustoloni YM, Cunha RV, Dorval ME, Oshiro ET, Pontes ER, Oliveira AL, et al. Comparison of conventional methods for diagnosis of visceral leishmaniasis in children of the Center-West Region of Brazil. Braz J Infect Dis 2007;11:106-9.

45. Liberopoulos E, Kei A, Apostolou F, Elisaf M. Autoimmune manifestations in patients with visceral leishmaniasis. J Microbiol Immunol Infect 2013;46:302-5.

46. Makaritsis KP, Gatselis NK, Ioannou M, Petinaki E, Dalekos GN. Polyclonal hypergammaglobulinemia and high smooth-muscle autoantibody titers with specificity against filamentous actin: Consider visceral leishmaniasis, not just autoimmune hepatitis. Int J Infect Dis 2009;13:e157-60.

47. Saitis A, Gatselis NK, Dalekos GN. Leishmaniasis-associated haemophagocytic syndrome revisited: Not an uncommon clinical presentation of leishmaniasis. J Med Cases 2012;3:315-8.

48. Voulgari PV, Pappas GA, Liberopoulos EN, Elisaf M, Skopouli FN, Drosos AA. Visceral leishmaniasis resembling systemic lupus erythematosus. Ann Rheum Dis 2004;63:1348-9.

49. Galvão-Castro B, Sá Ferreira JA, Marzochi KF, Marzochi MC, Coutinho SG, Lambert PH. Polyclonal B cell activation, circulating immune complexes and autoimmunity in human american visceral leishmaniasis. Clin Exp Immunol 1984;56:58-66.

50. Cota GF, de Sousa MR, de Freitas Nogueira BM, Gomes LI, Oliveira E, et al. Comparison of parasitological, serological, and molecular tests for visceral leishmaniasis in HIV-infected patients: A cross-sectional delayed-type study. Am J Trop Med Hyg 2013;89:570-7.

51. Reed SG, Shreffler WG, Burns JM Jr, Scott JM, Orge Mda G, Ghalib HW, et al. An improved serodiagnostic procedure for visceral leishmaniasis. Am J Trop Med Hyg 1990;43:632-9.

52. Cañavate C, Herrero M, Nieto J, Cruz I, Chicharro C, Aparicio P, et al. Evaluation of two rK39 dipstick tests, direct agglutination test, and indirect fluorescent antibody test for diagnosis of visceral leishmaniasis in a new epidemic site in highland Ethiopia. Am J Trop Med Hyg 2011;84:102-6.

53. de Assis TS, Braga AS, Pedras MJ, Oliveira E, Barral A, de Siqueira IC, et al. Multi-centric prospective evaluation of rk39 rapid test and direct 
agglutination test for the diagnosis of visceral leishmaniasis in Brazil. Trans R Soc Trop Med Hyg 2011;105:81-5.

54. Bern C, Haque R, Chowdhury R, Ali M, Kurkjian KM, Vaz L, et al. The epidemiology of visceral leishmaniasis and asymptomatic leishmanial infection in a highly endemic Bangladeshi village. Am J Trop Med Hyg 2007;76:909-14.

55. Maia Z, Lírio M, Mistro S, Mendes CM, Mehta SR, Badaro R. Comparative study of rK39 Leishmania antigen for serodiagnosis of visceral leishmaniasis: Systematic review with meta-analysis. PLoS Negl Trop Dis 2012;6:e1484.

56. Kumar R, Pai K, Pathak K, Sundar S. Enzyme-linked immunosorbent assay for recombinant K39 antigen in diagnosis and prognosis of Indian visceral leishmaniasis. Clin Diagn Lab Immunol 2001;8:1220-4.

57. Houghton RL, Petrescu M, Benson DR, Skeiky YA, Scalone A, Badaró R, et al. A cloned antigen (recombinant K39) of Leishmania chagasi diagnostic for visceral leishmaniasis in human immunodeficiency virus type 1 patients and a prognostic indicator for monitoring patients undergoing drug therapy. J Infect Dis 1998;177:1339-44.

58. Sundar S, Maurya R, Singh RK, Bharti K, Chakravarty J, Parekh A, et al. Rapid, noninvasive diagnosis of visceral leishmaniasis in India: Comparison of two immunochromatographic strip tests for detection of anti-K39 antibody. J Clin Microbiol 2006;44:251-3.

59. Sundar S, Singh RK, Bimal SK, Gidwani K, Mishra A, Maurya R, et al. Comparative evaluation of parasitology and serological tests in the diagnosis of visceral leishmaniasis in India: A phase III diagnostic accuracy study. Trop Med Int Health 2007;12:284-9.

60. Boelaert M, El-Safi S, Hailu A, Mukhtar M, Rijal S, Sundar S, et al. Diagnostic tests for kala-azar: A multi-centre study of the freezedried DAT, rK39 strip test and KAtex in East Africa and the Indian subcontinent. Trans R Soc Trop Med Hyg 2008;102:32-40.

61. Sundar S, Agrawal S, Pai K, Chance M, Hommel M. Detection of leishmanial antigen in the urine of patients with visceral leishmaniasis by a latex agglutination test. Am J Trop Med Hyg 2005;73:269-71.

62. Ruiter CM, Veer CV, Leeflang MM, Deborggraeve S, Lucas C, Adams ER. Major article: Molecular tools for diagnosis of visceral leishmaniasis: Systematic review and meta-analysis of diagnostic test accuracy. J Clin Microbiol 2014;52:3147-55.

63. Antinori S, Calattini S, Longhi E, Bestetti G, Piolini R, Magni C, et al. Clinical use of polymerase chain reaction performed on peripheral blood and bone marrow samples for the diagnosis and monitoring of visceral leishmaniasis in HIV-infected and HIV-uninfected patients: A single-center, 8-year experience in Italy and review of the literature. Clin Infect Dis 2007;44:1602-10.

64. Salam MA, Mondal D, Kabir M, Ekram AR, Haque R. PCR for diagnosis and assessment of cure in kala-azar patients in Bangladesh. Acta Trop 2010;113:52-5.

65. Pourabbas B, Ghadimi Moghadam A, Pouladfar G, Rezaee Z, Alborzi A. Quantification of Leishmania infantum kinetoplast DNA for monitoring the response to meglumine antimoniate therapy in visceral leishmaniasis. Am J Trop Med Hyg 2013;88:868-71.

66. Cruz I, Chicharro C, Nieto J, Bailo B, Cañavate C, Figueras MC, et al. Comparison of new diagnostic tools for management of pediatric Mediterranean visceral leishmaniasis. J Clin Microbiol 2006;44:2343-7.

67. Deborggraeve S, Boelaert M, Rijal S, De Doncker S, Dujardin JC, Herdewijn P, et al. Diagnostic accuracy of a new Leishmania PCR for clinical visceral leishmaniasis in Nepal and its role in diagnosis of disease. Trop Med Int Health 2008;13:1378-83.

68. Bern C, Adler-Moore J, Berenguer J, Boelaert M, den Boer M, Davidson RN, et al. Liposomal amphotericin B for the treatment of visceral leishmaniasis. Clin Infect Dis 2006;43:917-24.

69. Sundar S, Mehta H, Suresh AV, Singh SP, Rai M, Murray HW. Amphotericin B treatment for Indian visceral leishmaniasis: Conventional versus lipid formulations. Clin Infect Dis 2004;38:377-83.

70. Meyerhoff A. U.S. Food and Drug Administration approval of AmBisome (liposomal amphotericin B) for treatment of visceral leishmaniasis. Clin Infect Dis 1999;28:42-8.

71. Lachaud L, Bourgeois N, Plourde M, Leprohon P, Bastien P, Ouellette M. Parasite susceptibility to amphotericin B in failures of treatment for visceral leishmaniasis in patients coinfected with HIV type 1 and Leishmania infantum. Clin Infect Dis 2009;48:16-22.

72. Jarvis JN, Lockwood DN. Clinical aspects of visceral leishmaniasis in HIV infection. Curr Opin Infect Dis 2013;26:1-9.

73. Molina I, Falcó V, Crespo M, Riera C, Ribera E, Curran A, et al. Efficacy of liposomal amphotericin B for secondary prophylaxis of visceral leishmaniasis in HIV-infected patients. J Antimicrob Chemother 2007;60:837-42.

74. Yardley V, Croft SL. A comparison of the activities of three amphotericin B lipid formulations against experimental visceral and cutaneous leishmaniasis. Int J Antimicrob Agents 2000;13:243-8.

75. Hamill RJ. Amphotericin B formulations: A comparative review of efficacy and toxicity. Drugs 2013;73:919-34.

76. Moyssakis I, Vassilakopoulos TP, Sipsas NV, Perakis A, Petrou A, Kosmas N, et al. Reversible dilated cardiomyopathy associated with amphotericin B treatment. Int J Antimicrob Agents 2005;25:444-7.

77. Georgiadou SP, Kontoyiannis DP, Sipsas NV. Subclinical tumor lysis-like syndrome during treatment of visceral leishmaniasis with low-dose intermittent liposomal amphotericin B. Central Eur J Med 2012;7:305-9.

78. den Boer M, Davidson RN. Treatment options for visceral leishmaniasis. Expert Rev Anti Infect Ther 2006;4:187-97.

79. Sundar S, More DK, Singh MK, Singh VP, Sharma S, Makharia A, et al. Failure of pentavalent antimony in visceral leishmaniasis in India: Report from the center of the Indian epidemic. Clin Infect Dis 2000;31:1104-7.

80. Rijal S, Chappuis F, Singh R, Bovier PA, Acharya P, Karki BM, et al. Treatment of visceral leishmaniasis in south-eastern Nepal: Decreasing efficacy of sodium stibogluconate and need for a policy to limit further decline. Trans R Soc Trop Med Hyg 2003;97:350-4.

81. Sundar S. Drug resistance in Indian visceral leishmaniasis. Trop Med Int Health 2001;6:849-54.

82. Herwaldt BL, Berman JD. Recommendations for treating leishmaniasis with sodium stibogluconate (Pentostam) and review of pertinent clinical studies. Am J Trop Med Hyg 1992;46:296-306.

83. Bhattacharya SK, Sinha PK, Sundar S, Thakur CP, Jha TK, Pandey K, et al. Phase 4 trial of miltefosine for the treatment of Indian visceral leishmaniasis. J Infect Dis 2007;196:591-8.

84. Sundar S, Olliaro PL. Miltefosine in the treatment of leishmaniasis. Clinical evidence for informed clinical risk management. Ther Clin Risk Manag 2007;3:733-40.

85. Seifert K, Pérez-Victoria FJ, Stettler M, Sánchez-Cañete MP, Castanys S, Gamarro F, et al. Inactivation of the miltefosine transporter, LdMT, causes miltefosine resistance that is conferred to the amastigote stage of Leishmania donovani and persists in vivo. Int J Antimicrob Agents 2007;30:229-35.

86. Pérez-Victoria FJ, Sánchez-Cañete MP, Seifert K, Croft SL, Sundar S, Castanys S, et al. Mechanisms of experimental resistance of Leishmania to miltefosine: Implications for clinical use. Drug Resist Updat 2006;9:26-39.

87. Sundar S, Singh A, Rai M, Prajapati VK, Singh AK, Ostyn B, et al. Efficacy of miltefosine in the treatment of visceral leishmaniasis in India after a decade of use. Clin Infect Dis 2012;55:543-50.

88. Pandey BD, Pandey K, Kaneko O, Yanagi T, Hirayama K. Relapse of visceral leishmaniasis after miltefosine treatment in a Nepalese patient. Am J Trop Med Hyg 2009;80:580-2.

89. Rijal S, Ostyn B, Uranw S, Rai K, Bhattarai NR, Dorlo TP, et al. Increasing failure of miltefosine in the treatment of Kala-azar in Nepal and the potential role of parasite drug resistance, reinfection, or noncompliance. Clin Infect Dis 2013;56:1530-8.

90. Sundar S, Jha TK, Thakur CP, Sinha PK, Bhattacharya SK. Injectable paromomycin for Visceral leishmaniasis in India. N Engl J Med 2007;356:2571-81

91. Musa AM, Younis B, Fadlalla A, Royce C, Balasegaram M, Wasunna M, et al. Paromomycin for the treatment of visceral leishmaniasis in Sudan: A randomized, open-label, dose-finding study. PLoS Negl Trop Dis 2010 26;4:e855.

92. Monge-Maillo B, López-Vélez R. Topical paromomycin and gentamicin for new world cutaneous leishmaniasis in Panama. Am J Trop Med Hyg 2014;90:1191.

93. Sundar S, Rai M, Chakravarty J, Agarwal D, Agrawal N, Vaillant M, et al. New treatment approach in Indian visceral leishmaniasis: Single-dose liposomal amphotericin B followed by short-course oral miltefosine. Clin Infect Dis 2008;47:1000-6.

94. Melaku Y, Collin SM, Keus K, Gatluak F, Ritmeijer K, Davidson RN. Treatment of kala-azar in southern Sudan using a 17-day regimen of sodium stibogluconate combined with paromomycin: A retrospective comparison with 30-day sodium stibogluconate monotherapy. Am J Trop Med Hyg 2007;77:89-94. 
95. Sundar S, Sinha PK, Rai M, Verma DK, Nawin K, Alam S, et al. Comparison of short-course multidrug treatment with standard therapy for visceral leishmaniasis in India: An open-label, non-inferiority, randomised controlled trial. Lancet $2011 ; 377: 477-86$
How to cite this article: Georgiadou SP, Makaritsis KP, Dalekos GN. Leishmaniasis revisited: Current aspects on epidemiology, diagnosis and treatment. J TransI Intern Med 2015;3:43-50

Source of Support: NIL, Conflict of Interest: NIL 